\title{
Association of single nucleotide polymorphism (rs741301) of the ELMO1 gene with diabetic kidney disease in Polish patients with type 2 diabetes: a pilot study
}

\author{
Hanna Kwiendacz'1, Katarzyna Nabrdalik', Piotr Adamczyk2, Dariusz Moczulski³ , Hanna Moczulska ${ }^{3,4}$, \\ Wanda Trautsolt ${ }^{1}$, Sylwia Górczyńska-Kosiorz', Władysław Grzeszczak', Janusz Gumprecht ${ }^{1}$
}

${ }^{1}$ Department of Internal Medicine, Diabetology, and Nephrology in Zabrze, Faculty of Medical Sciences in Zabrze, Medical University of Silesia, Katowice, Poland

${ }^{2}$ Department of Pediatrics, Faculty of Medical Sciences in Zabrze, Medical University of Silesia, Katowice, Poland

${ }^{3}$ Department of Internal Medicine and Nephrodiabetology, Medical University of Łódź, Łódź, Poland

${ }^{4}$ Department of Clinical Genetics, Medical University of Łodź, Łódź, Poland

\begin{abstract}
Introduction: Multifactorial pathogenesis of diabetic kidney disease (DKD) consists of a combination of metabolic, environmental, and genetic factors. A genome-wide association study has shown that ELMO1 is a candidate gene for DKD occurrence and progression. The aim of this study was to assess the association of a single nucleotide polymorphism (rs741301) of the ELMO1 gene with DKD in Polish patients with type 2 diabetes (T2DM).

Material and methods: This was a case/control study of 272 T2DM patients with or without DKD. Patients were divided into groups depending on DKD definition according to the American Diabetes Association (ADA) and the National Kidney Foundation (NKF). The association of the rs741301 polymorphism with DKD was assessed in the whole study group as well as in the subgroups stratified according to the presence of DKD.

Results: There was no association between rs741301 polymorphisms and the presence of DKD in relation to the ADA definition $(p=0.6)$ or the NKF definition $(p=0.5)$ of DKD and with estimated glomelural filtration rate (eGFR) value reflecting the stage of the chronic kidney disease $(\mathrm{p}=0.8)$.

Conclusions: Even though the results of this study are negative, there is still a great need for larger studies assessing the genetic susceptibility to DKD to identify patients who are particularly prone to this complication. (Endokrynol Pol 2020; 71 (1): 66-72)

Key words: diabetes mellitus type 2; diabetic kidney disease; ELMO1 gene; rs741301; SNP
\end{abstract}

\section{Introduction}

Diabetes mellitus is an enormous health problem. Its prevalence is estimated to rise from 425 million people in 2017 to 629 million by 2045 [1]; it has been described as a silent pandemic of the $21^{\text {st }}$ century [2]. Approximately $40 \%$ of those with type 2 diabetes (T2DM) develop diabetic kidney disease (DKD), which is a leading cause of end-stage renal disease (ESRD) globally [3]. Most of these patients actually die from cardiovascular diseases before they reach this final stage of chronic kidney disease (CKD) [4]. In Poland, there are almost 3 million people living with diabetes, and the precise occurrence of DKD is difficult to estimate because of a lack of specific registries; however, it is known that almost $44 \%$ of all ESRD is due to diabetes [5].

Diabetic kidney disease is recognised based on the existence of persistent increased urine albumin excretion and/or decreased estimated glomerular filtration rate (eGFR) when other causes of CKD are excluded [3]. Diabetic kidney disease is often diagnosed at advanced stages [6] because it may have no clinical manifestation until ESRD occurs; thus, there is an unmet need to identify biomarkers that identify patients at early stages, to implement proper treatment. The multifactorial pathogenesis of DKD consists of a combination of metabolic, environmental, and genetic factors [2]. There are no universal methods to identify patients who are prone to this complication; however, in view of the indisputable role of genetic factors, searching for candidate genes seems to be critical for scientific research.

A prior genome-wide association study (GWAS) identified genes with polymorphisms associated with increased incidence of DKD [7]. However, further studies to prove the role of these polymorphisms in DKD occurrence and progression in different diabetic populations are needed, in order to guide strategies that prevent and treat DKD. There are relatively few 
Polish studies which emphaze gene polymorphisms and DKD; some proved an association [8,9], but others did not $[10,11]$.

A genome-wide association study has shown the engulfment and cell motility 1 (ELMO1) gene to be a potential candidate gene for the development of DKD in various populations of patients, but it has not yet been studied in a Polish population. ELMO1 is located in humans on chromosome 7 , and the most significant single nucleotide polymorphism (SNP) is rs741301 [12-15]. Engulfment and Cell Motility (ELMO) is a soluble cytoplasmic multifunctional signalling protein consisting of 720 amino acids. It promotes cytoskeleton reorganisation [16], cell migration [17], and phagocytosis of apoptotic cells [18].

Sharma et al. recently published an elegant study using animal models to identify the role of ELMO1 in the renal development of zebrafish under hyperglycaemia. They confirmed the animal data with immunohistochemical analysis of human kidneys from patients with DKD. Those authors concluded that the overexpression of the ELMO1 gene occurs due to the glomerular protection and survival of renal cells by decreasing apoptosis under hyperglycaemic conditions [19].

Subsequent studies confirmed the association of different SNP variants in the ELMO1 gene with susceptibility to $\mathrm{DKD}$ in patients from various populations: African Americans [20], European Americans [21], American Indians [22], Mexican Americans [23], Tunisian Arabs [24], as well as citizens of China [25], India [26-27], Iran [28], and Malaysia [29]. Unfortunately, it is impossible to draw a unified conclusion from the outcomes because these studies were different in terms of methodology and definition of DKD. Some of these patients presented with T2DM [20, 22-29], but others with type 1 diabetes mellitus [21]. Some of the authors used the DKD definition according to ADA $[3,28]$ whereas others according to NKF [12, 21, 25, 26, 30]. This discrepancy may be caused by a lack of coherence between DKD definitions across leading international diabetology and nephrology associations $[3,30]$. The American Diabetes Association (ADA) suggests the diagnosis of DKD if the urine albumin-to-creatinine ratio (UACR) is $\geq 30 \mathrm{mg} / \mathrm{g}$ [3], and the National Kidney Foundation (NKF) diagnosis DKD if UACR is $\geq 30 \mathrm{mg} / \mathrm{g}$ only in patients with retinopathy; UACR $>300 \mathrm{mg} / \mathrm{g}$ in regardless of this complication [30]. Polish guidelines for the management of diabetes emphasise that screening for increased urinary albumin excretion should be performed annually [31]. In light of the positive GWAS outcomes in relation to the ELMO1 gene and the contradictory outcomes of follow-up studies - as well as the lack of studies performed in a Polish population - this study assessed the association of rs741301 ELMO1 gene variants (reference sequence NC_000007.14:g.36878390C > T) with DKD in a group of Polish T2DM patients (the industrial region of Silesia, Poland).

\section{Material and methods}

\section{Patients}

This was a case/control study. We invited to participate in the study 329 consecutive, patients suffering from T2DM for at least 10 years, treated in the Diabetology Outpatient Clinic in Zabrze, Poland. First of all, patients were divided into two study groups depending on the presence (the study group) or the absence of DKD (the control group). We initially used DKD diagnosis criteria proposed by ADA (UACR $\geq 30 \mathrm{mg} / \mathrm{g}$ present in two out of three urine samples). Furthermore, we chose to use DKD diagnosis criteria proposed by NKF, which were more restricted than those proposed by ADA, and we further divided the study group into a study subgroup of patients (UACR $\geq 30 \mathrm{mg} / \mathrm{g}$ in two out of three specimens when coexisting diabetic retinopathy was present or UACR $>300 \mathrm{mg} / \mathrm{g}$ in patients regardless of diabetic retinopathy) and a control subgroup of patients (without retinopathy and with UACR $<30 \mathrm{mg} / \mathrm{g})$. The exclusion criteria for both study groups were as follows: type 1 diabetes mellitus, chronic interstitial nephritis, chronic glomerulonephritis, cancer, or lack of informed consent. The study was approved by the Ethical Committee of the Medical University of Silesia and performed in accordance with ethical standards and with the 1964 Helsinki declaration as well as its later amendments. All participants gave written, informed consent.

\section{Methods}

Eligible patients were invited to participate in the study. During the first study visit, medical history collection based on medical documentation from the Diabetology Outpatient Clinic and a routine physical examination were performed the anthropometric parameters such as height $(\mathrm{m})$ and weight $(\mathrm{kg})$ being measured by standard methods, and the body mass index (BMI) was calculated $\left(\mathrm{kg} / \mathrm{m}^{2}\right)$. Blood pressure was measured (after five minutes of rest) three times, each five minutes apart in a sitting position by Microlife BP AG1-20 sphygmomanometer. Blood samples were collected from the subjects for biochemical analysis and DNA extraction. Haemoglobin $\mathrm{A}_{1 \mathrm{c}}$ was measured using high-performance liquid chromatography (HPLC), and the outcome was expressed in National Glycohemoglobin Standardisation Program/Diabetes Control and Complication Trial units [32]. Serum creatinine was determined with Jaffe's method and estimated glomelural filtration rate (eGFR) per $1.73 \mathrm{~m}^{2}$ and was calculated according to the CKD-EPI formula [33]; these results were classified into five stages of the disease (G1-G5) [34]. The UACR was estimated using immunoturbidimetric methods and was drawn from the patients' medical history (we analysed three morning urine samples collected over six months). Diabetic kidney disease was recognised based on elevated UACR after excluding other possible causes of elevated albuminuria (on the basis of physical examination and present and past medical history). Patients were examined by the same ophthalmologist to determine the presence and severity of diabetic retinopathy.

\section{SNP genotyping}

Genomic DNA was extracted from patients' peripheral blood lymphocytes as follows: $4 \mathrm{~mL}$ of venous blood was collected into S-Monovette tubes (Sarstedt, $6.4 \mathrm{mg}$ of potassium EDTA) and centrifuged for 10 minutes (1000 rpm, Sigma 3K15); the buffy coat was aspirated into $2 \mathrm{ml}$ cryovials and stored at $-20^{\circ} \mathrm{C}$ until DNA isolation. After defrosting, the material was transferred to $50 \mathrm{ml}$ Falcon tubes (Sarstedt) and erythrocyte lysis buffer was added $(0.32 \mathrm{~mol} / \mathrm{L}$ sucrose, $0.01 \mathrm{mmol} / \mathrm{L}$ TrisHCL, $5 \mathrm{mmol} / \mathrm{L}$ magnesium 


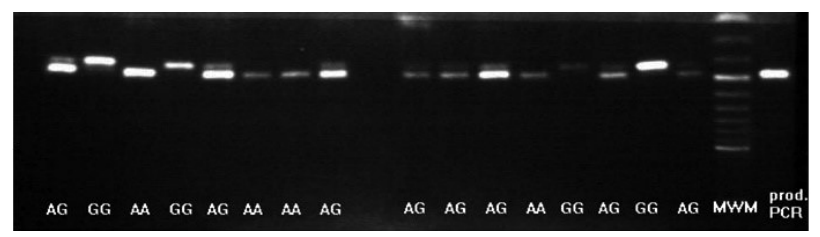

Figure 1. Distribution of allele A ang G of the ELMO1 gene documented via ViberLourmet with a UV transilluminator

chloride, and $1 \%$ Triton $\mathrm{X}-100)$. After 30 minutes of incubation at $4^{\circ} \mathrm{C}$, the material was centrifuged ( 10 minutes, $3000 \mathrm{rpm}, 4^{\circ} \mathrm{C}$, Sigma 3K15). The supernatant was removed, and the leucocyte sediment was purified with lysis buffer again as before. DNA was extracted from the leucocyte sediment via a DNAzol Reagent (Life Technologies, USA) in accordance with the manufacturer's instructions. The quality and quantity of DNA was examined with Gen Quant II (Pharmacia Biotech, Sweden).

The polymerase chain reaction (PCR) identified 188 base pairs (bp) with an rs741301 polymorphism. The reaction substrates were as follows: $2 \mu \mathrm{g}$ DNA, $1.55 \mathrm{mmol} / \mathrm{L}$ magnesium chloride, $2 \mu \mathrm{g}$ deoxynucleoside triphosphates, $2 \mu \mathrm{g}$ primer ELMO F $5^{\prime}$ - CAC AAC TGT CTC AAC AGT CTG - 3', and $2 \mu \mathrm{g}$ primer ELMO R 5' - GCA ATA GAT TTT ATG AGG TGG TAG $-3^{\prime}$, and 0.5 units of DNA polymerase DyNAzyme TMII (Finnzymes). To create a cutting spot for the Alu I restriction enzyme, $C$ was substituted with $T$ in the primer. PCR thermal cycles were as follows: denaturation at $94^{\circ} \mathrm{C}$ for 5 minutes and then 35 cycles: 1 minute at $94^{\circ} \mathrm{C}, 1$ minute at $55^{\circ} \mathrm{C}$, and $1.5 \mathrm{~min}$ utes at $72^{\circ} \mathrm{C}$; the end was 10 minutes at $72^{\circ} \mathrm{C}$. Digestion with $\mathrm{Alu}$ I restriction enzyme lasted 2 hours at $37^{\circ} \mathrm{C}$. The PCR product was dispersed via electrophoresis on agarose gel with $3 \%$ ethidium bromide enabling DNA visualisation in UV. Allele G created a cutting spot for Alu I, resulting in two DNA bands (164 and $24 \mathrm{bp}$ ). Allele A had no cutting spot for the enzyme, and the DNA band was $188 \mathrm{bp}$ long. The method was validated within the laboratory. The length of the fragments was estimated in comparison with a $50 \mathrm{bp}$ long DNA Ladder (Fermentas). The results were documented via a ViberLourmet with a UV transilluminator. Figure 1 presents the distribution of allele $\mathrm{G}$ and $\mathrm{A}$ as well as the homozygous AA and GG genotypes and the heterozygous genotype AG.

\section{Statistical analysis}

All statistical calculations were performed using Microsoft Office Excel and Statistica 12.0 (StatSoft Inc., USA) software. The Shapiro-Wilk normality test was used to establish the distribution of quantitative variables. Descriptive statistics for continuous parameters of normal distribution are presented as the arithmetic means (standard deviation (SD). Median values with interquartile range are presented for continuous data that did not have normal distribution. Absolute values and percentages are given for categorical and qualitative variables.

Comparative analyses were performed with the $t$-test or Mann-Whitney U-test for variables with normal distribution and other types of distribution, respectively. Accordance with Hardy-Weinberg equilibrium was tested with Pearson's $\chi^{2}$ test with Yates correction. A p value of $<0.05$ was considered to be statistically significant.

\section{Results}

From the total of 329 eligible patients enrolled into the study, 57 were not included for further analysis for various reasons listed in Figure 2. There were 272 patients enrolled into the final analysis [170 women $(62.5 \%)$ ] in a mean (SD) age of 63.7 (8) years and with mean (SD) duration of T2DM of 14.1 (6.3) years. Our first intention was to divide the whole study group into two groups; namely, the study group $(\mathrm{n}=117)$ consisting of patients with T2DM and DKD defined according to ADA DKD criteria (which are less restricted than DKD diagnosis criteria proposed by NKF, which require retinopathy coexistence or higher UACR value for diagnosis) and the control group $(n=155)$ of patients with T2DM but without DKD. Because there was no association of studied polymorphism found when these groups were analysed, we decided to check whether there could be an association found when the diagnosis criteria for DKD were exacerbated, as in the case of criteria proposed by NKF, in which the UACR has to be higher or coexisting retinopathy is required. Hence, we took a closer look into the study group of 117 patients with DKD according to ADA criteria, and the subgroup of patients with DKD according to NKF criteria emerged $(\mathrm{n}=79)$. From the control group of patients without DKD we distinguished a control subgroup $(n=72)$ of patients without retinopathy.

The basic demographic and clinical characteristics of the study and control groups are shown in Table 1 and Table 2 . There were 55 patients with UACR $30-300 \mathrm{mg} / \mathrm{g}$ and 62 with UACR $>300 \mathrm{mg} / \mathrm{g}$ in the study group (Tab. 1). There were no patients who fulfilled the ADA criteria of DKD related solely to lower eGFR, i.e. there were 27 patients with decreased eGFR below $60 \mathrm{~mL} / \mathrm{min} / 1.73 \mathrm{~m}^{2}$ who did not have elevated UACR but had other causes of CKD (such as recurrent infections and chronic interstitial nephritis) and therefore were enrolled into the control group. The genotype frequency distribution among the study and control groups and subgroups were in agreement with the Hardy-Weinberg equilibrium (Tab. S1 and S2 in supplementary materials, respectively). There was no association between the rs741301 polymorphism and the presence of DKD in the control group (Tab. 3, p = 0.6) nor with eGFR reflecting the CKD stage (Tab. $4, \mathrm{p}=0.8$ ). There was also no association between the examined SNP and DKD in the study subgroup (DKD defined according to NKF criteria) (Tab. 5, $\mathrm{p}=0.5$ ). Additionally, there were no significant differences between studied groups according to gender $(\mathrm{p}=0.6)$ or smoking status $(p=0.09)$. Moreover, the studied groups did not differ significantly in terms of hypertension $(p=0.2$, Tab. 1$)$ and ACEI use ( $p=0.09$, Tab. 1$)$.

\section{Discussion}

Diabetic kidney disease is the leading cause of ESRD and is often diagnosed at its late stages moreover genetic factors have a clear role in its development. Therefore, genetic markers can potentially be used for early diagnosis of DKD. The GWAS study has shown 


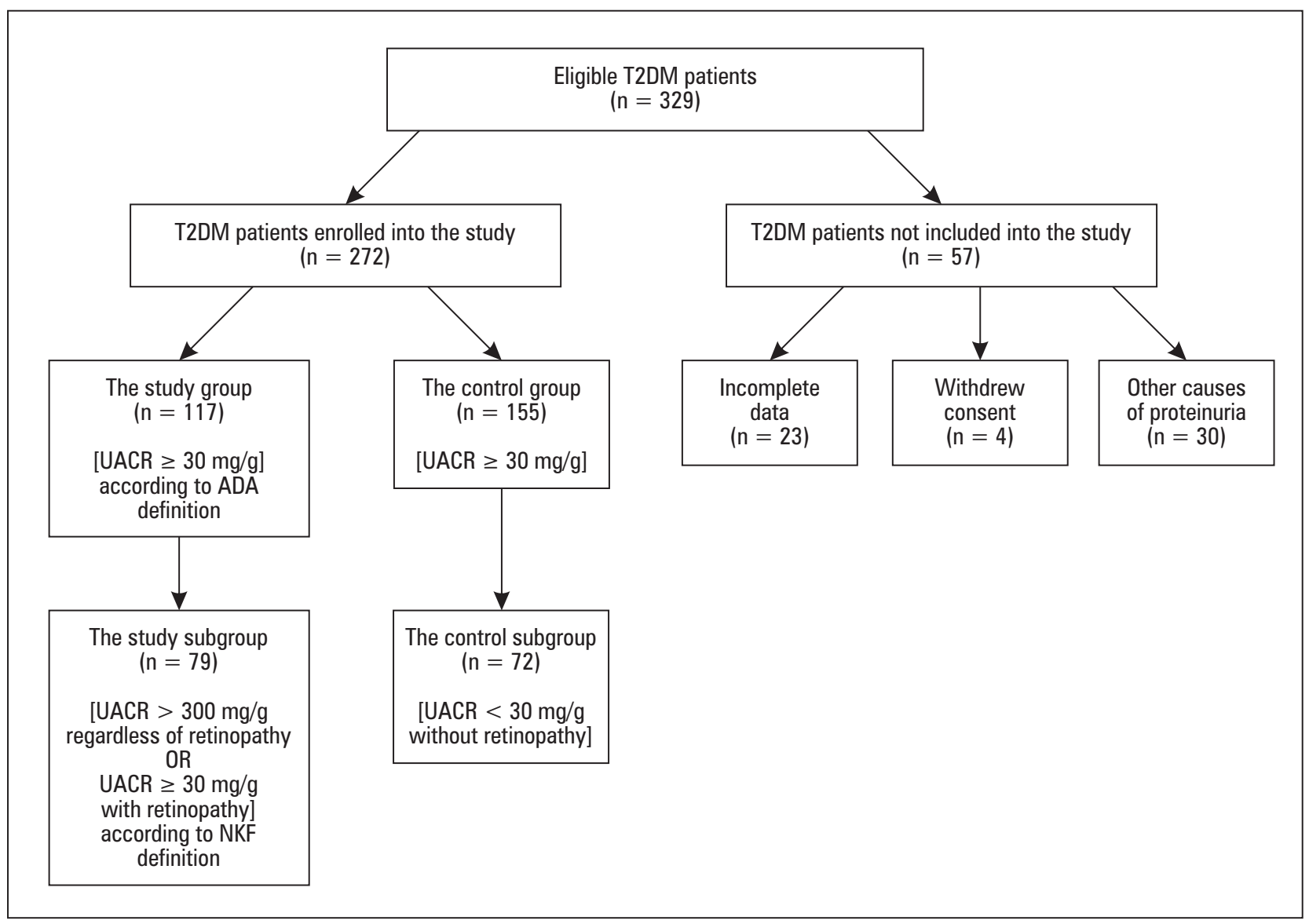

Figure 2. Patient's assignment to groups. T2DM - type 2 diabetes mellitus; UACR - urine albumin/creatinine ratio; ADA - American Diabetes Association; NKF — National Kidney Foundation

Table 1. Demographic and clinical characteristics of study and control group

\begin{tabular}{|c|c|c|c|}
\hline Parameters & Study $(n=117)$ & Control $^{b}(n=155)$ & $\mathbf{p}$ \\
\hline Age (years) & $63.1(8.4)$ & $64.1(7.7)$ & 0.35 \\
\hline Diabetes duration (years) & $12.3(6.7)$ & $15.5(5.7)$ & 0.05 \\
\hline $\mathrm{BMI}\left[\mathrm{kg} / \mathrm{m}^{2}\right]$ & $28.82(4.5)$ & $29.33(4.3)$ & 0.38 \\
\hline SBP [mm Hg] & $151(22.3)$ & $145.3(19.9)$ & 0.03 \\
\hline $\mathrm{DBP}[\mathrm{mm} \mathrm{Hg}]$ & $82.5(12.4)$ & $85.3(11.9)$ & 0.07 \\
\hline $\mathrm{HbA}_{1 \mathrm{c}}(\%)[\mathrm{mmol} / \mathrm{mol}]$ & $\begin{array}{c}8.98(1.9) \\
(75[15.9])\end{array}$ & $\begin{array}{l}8.81(1.6) \\
(73[13.3])\end{array}$ & 0.03 \\
\hline Creatinine $[\mu \mathrm{mol} / \mathrm{L}]$ & $115.93(114.8)$ & $71.92(31.8)$ & 0.0013 \\
\hline $\mathrm{eGFR}\left[\mathrm{mL} / \mathrm{min} / 1.73 \mathrm{~m}^{2}\right]$ & $73.48(29.8)$ & $81.52(22.0)$ & 0.0004 \\
\hline UACR $[\mathrm{mg} / \mathrm{g}]$ & $770.3(835.7)$ & $11.75(9.5)$ & 0.0000 \\
\hline Number of patients with UACR in range of $30-300 \mathrm{mg} / \mathrm{g}(\mathrm{n})$ & 55 & 0 & 0.0000 \\
\hline Number of patients with UACR $>300 \mathrm{mg} / \mathrm{g}(\mathrm{n})$ & 62 & 0 & 0.0000 \\
\hline Hypertension [n (\%)] & $110(94)$ & $139(90)$ & 0.2 \\
\hline ACEI [n (\%)] & $49(42)$ & $50(32)$ & 0.09 \\
\hline
\end{tabular}

ACEI — angiotensin-converting-enzyme inhibitors; BMI — body mass index; DBP — diastolic blood pressure; eGFR — estimated glomerular filtration rate; $\mathrm{HbA}_{1 \mathrm{c}}$ — haemoglobin $\mathrm{A}_{1 \mathrm{c}} ; \mathrm{n}$ - number of patients; $\mathrm{p}$ - statistical significance; SBP — systolic blood pressure; UACR - urinary albumin/creatinine ratio; ${ }^{a} D K D(+)$ according to the ADA 2018 definition; ${ }^{b} D K D(-)$ according to the ADA 2018 definition

Data are presented as mean (SD) 
Table 2. Demographic and clinical characteristics of study and control subgroup

\begin{tabular}{|c|c|c|c|}
\hline Parameters & Study subgroup ${ }^{\mathrm{a}}(\mathbf{n}=79)$ & Control subgroup $(\mathrm{n}=72)$ & $\mathbf{p}$ \\
\hline Age (years) & $62.84(7.94)$ & $65.75(7.06)$ & 0.41 \\
\hline Diabetes duration (years) & $14.9(6.7)$ & $16.75(5.1)$ & 0.11 \\
\hline $\mathrm{BMI}\left[\mathrm{kg} / \mathrm{m}^{2}\right]$ & $28.97(4.8)$ & $28.86(4.3)$ & 0.56 \\
\hline SBP [mm Hg] & $153.8(25.7)$ & $144.1(19.9)$ & 0.05 \\
\hline $\mathrm{DBP}[\mathrm{mm} \mathrm{Hg}]$ & $83.5(14.2)$ & $84.6(11.9)$ & 0.71 \\
\hline $\mathrm{HbA}_{1 \mathrm{c}}(\%)[\mathrm{mmol} / \mathrm{mol}]$ & $\begin{array}{c}9.25(1.8) \\
{[78(15.2)]}\end{array}$ & $\begin{array}{c}9.11(1.5) \\
{[76(12.2)]}\end{array}$ & 0.65 \\
\hline Creatinine $[\mu \mathrm{mol} / \mathrm{L}]$ & $103.4(55.4)$ & $79.4(67.5)$ & 0.006 \\
\hline $\mathrm{eGFR}\left[\mathrm{mL} / \mathrm{min} / 1.73 \mathrm{~m}^{2}\right]$ & $71.2(30.0)$ & $79.4(19.1)$ & 0.008 \\
\hline UACR $[\mathrm{mg} / \mathrm{g}]$ & $926.9(1214.3)$ & $12.39(12.1)$ & 0.0000 \\
\hline
\end{tabular}

Table 3. Distribution of the genotype frequencies of rs741301 ELMO1 gene in the study and control group ( $p=0.6$; based on $\chi^{2}$ Pearson test)

\begin{tabular}{lccc}
\hline Genotype & A/A & A/G & G/G \\
\hline Study & $53(45)$ & $48(41)$ & $16(14)$ \\
\hline Control & $78(50)$ & $61(40)$ & $16(10)$ \\
\hline
\end{tabular}

Data are presented as absolute values (percentages)
Table 5. Distribution of the genotype frequencies of rs741301 ELMO1 gene in the study and control subgroup $(p=0.5$; based on $\chi^{2}$ Pearson test)

\begin{tabular}{lccc}
\hline Genotype & A/A & A/G & G/G \\
\hline Study subgroup $[\mathrm{n}(\%)]$ & $36(46)$ & $35(44)$ & $8(10)$ \\
\hline Control subgroup $[\mathrm{n}(\%)]$ & $37(51)$ & $25(35)$ & $10(14)$ \\
\hline
\end{tabular}

Data are presented as numbers (percentages)

Table 4. Distribution of the genotype frequencies of rs741301 ELMO1 gene in relation to chronic kidney disease (CKD) stage $\left(p=0.8\right.$; based on $\chi^{2}$ Pearson test)

\begin{tabular}{|c|c|c|c|c|c|c|}
\hline \multirow[b]{2}{*}{ CKD stage } & \multirow{2}{*}{$\begin{array}{c}\text { G1 } \\
(n=83)\end{array}$} & \multirow{2}{*}{$\begin{array}{c}\text { G2 } \\
(n=128)\end{array}$} & \multicolumn{2}{|c|}{ G3 } & \multirow{2}{*}{$\begin{array}{c}\text { G4 } \\
(\mathrm{n}=8)\end{array}$} & \multirow{2}{*}{$\begin{array}{c}\text { G5 } \\
(n=4)\end{array}$} \\
\hline & & & $\begin{array}{c}\text { G3a } \\
(\mathrm{n}=\mathbf{3 3})\end{array}$ & $\begin{array}{c}\text { G3b } \\
(n=16)\end{array}$ & & \\
\hline Genotype AA [n (\%)] & $39(30)$ & $63(48)$ & $15(11)$ & $11(8)$ & $2(2)$ & $1(1)$ \\
\hline Genotype AG [n (\%)] & $36(33)$ & $49(45)$ & $13(11)$ & $4(4)$ & $4(4)$ & $3(3)$ \\
\hline Genotype GG [n (\%)] & $8(25)$ & $16(50)$ & $5(16)$ & $1(3)$ & $2(6)$ & $0(0)$ \\
\hline
\end{tabular}

Data are presented as absolute values (percentages)

that the rs741301 polymorphism of the ELMO1 gene is a candidate diagnostic gene for DKD. We chose rs741301 polymorphism of ELMO1 gene as a candidate gene for DKD based upon findings from previous studies, but these prior studies are contradictory [12, 20-29]. To the best of our knowledge, none of the prior studies assessed the role of the ELMO1 gene with DKD among Polish patients. Moreover, none of these studies applied the two available (ADA and NKF) definitions of DKD in one study. This makes it impossible to perform a direct comparison of the studies performed to date. Our study comprised 272 Polish T2DM patients from Silesia region. No association was seen between the rs741301 polymorphism of the ELMO1 gene and DKD regardless of the criteria used to diagnose DKD. The allelic frequency observed in the European population is G: 0.322 and A: 0.678 [35] and is comparable to the frequency seen in the presented study.

Even though this study obtained a negative result, our findings are consistent with some studies exploring the association of ELMO1 gene with DKD performed in other ethnic groups. Kim et al. examined almost 900 people of Mexican-American descent. Most suffered from T2DM, but the authors did not prove the association between ELMO1 and DKD. In that study, most of the patients had ESRD and diabetes as 
a cause of DKD diagnosed based on various criteria [23]. Similarly, Hanson et al. showed no association of the ELMO1 gene with DKD in Pima Indians of Arizona, who have a high rate of DKD. Thus, the association may be strongly dependent on genetic background. These authors studied 12 SNPs of the ELMO1 gene including rs741301 among 141 patients with DKD based on protein-to-creatinine ratio and 416 T2DM patients without DKD. The authors suggest that the relationship between ELMO1 gene variations and DKD may have some functional variants or complex and undiscovered interactions with other biological factors [22]. This study stays in line with Yadav et al. in northern India, who examined 417 T2DM patients of whom 202 presented DKD based on reduced eGFR and proteinuria exceeding $500 \mathrm{mg} /$ day along with retinopathy. They noticed a higher incidence of rs741301 in patients with diabetes compared to healthy controls, but there was no association of this variant with DKD [27]. Similarly, Yahya et al. examined 820 patients from Malaysia and concluded that SNP rs741301 does not contribute to DKD [29].

Other studies proved an association of rs741301 with DKD. Shimazaki et al. examined 94 patients with DKD (defined as an overt nephropathy - urinary albumin excretion rates $\geq 200 \mu \mathrm{g} / \mathrm{min}$ or UACR ratio $\geq 300 \mathrm{mg} / \mathrm{g}$ or chronic renal-replacement therapy) with coexisting diabetic retinopathy and 96 controls without renal dysfunction. They proved that the G allele and the GG genotype of the rs741301 variant of ELMO1 gene increases susceptibility to DKD and plays an important role both in the development and progression of this complication [12]. Mehrabzadeh et al. studied 300 Iranians (100 healthy volunteers, 100 with DKD defined as UACR $\geq 30 \mathrm{mg} / \mathrm{g}$ or protein excretion history due to diabetes, and 100 patients with T2DM without DKD, i.e. UACR $<30 \mathrm{mg} / \mathrm{g}$ ) [28]. They also found a key role of the G allele and the GG genotype of the rs741301 variant of the ELMO1 gene as a candidate marker for DKD susceptibility. Interestingly, contradictory conclusions were drawn by Wu et al. conducting a case-control study on a group of 200 unrelated T2DM Chinese patients (123 with DKD diagnosed as UACR $\geq 300 \mathrm{mg} / \mathrm{g}$ or renal replacement therapy; 77 patients with UACR $<30 \mathrm{mg} / \mathrm{g}$ as controls). Their results suggested that the risk allele of DKD is allele A and not allele G as in the other studies [25].

Our study has some limitations. Only one SNP was examined, and the sample size was relatively small; however, this is only a preliminary report, and larger studies may give more information, especially since there has been no such study performed among Polish patients with diabetes.

\section{Conclusion}

In conclusion, our study did not prove an association between DKD and the ELMO1 gene in Polish population of patients. There is still a great need for larger studies to identify patients who are particularly prone to this diabetic complication. We emphasise that negative studies are of great value in medicine; and such should not be underestimated because they can guide the direction of future studies [36].

\section{Funding source}

Statutory work of Silesian Medical University.

\section{References}

1. International Diabetes Federation. IDF Diabetes Atlas, 8th ed. Brussels 2017. https://www.diabetesatlas.org/ (30 August 2019).

2. Kharroubi AT, Darwish HM. Diabetes mellitus: The epidemic of the century. World J Diabetes. 2015; 6(6): 850-867, doi: 10.4239/wjd.v6.i6.850, indexed in Pubmed: 26131326.

3. American Diabetes Association. 11. Microvascular Complications and Foot Care: . Diabetes Care. 2019; 42(Suppl 1): S124-S138, doi: 10.2337/dc19-S011, indexed in Pubmed: 30559237.

4. Sharma A, Green JB, Dunning A, et al. TECOS Study Group. Causes of Death in a Contemporary Cohort of Patients With Type 2 Diabetes and Atherosclerotic Cardiovascular Disease: Insights From the TECOS Trial. Diabetes Care. 2017; 40(12): 1763-1770, doi: 10.2337/dc17-1091, indexed in Pubmed: 28986504.

5. Wierzba W, Karnafel W, Tyszko P, et al. Assessment of the incidence rate of end-stage renal disease in patients with and without diabetes in Poland. Ann Agric Environ Med. 2018; 25(3): 568-571, doi: 10.26444/aaem/89993, indexed in Pubmed: 30260172

6. Persson F, Rossing P. Diagnosis of diabetic kidney disease: state of the art and future perspective. Kidney Int Suppl. 2018; 8(1): 2-7, doi: 10.1016/j. kisu.2017.10.003, indexed in Pubmed: 30675433.

7. Ahlqvist E, van Zuydam NR, Groop LC, et al. The genetics of diabetic complications. Nat Rev Nephrol. 2015; 11(5): 277-287, doi: 10.1038/nrneph.2015.37, indexed in Pubmed: 25825086.

8. Nabrdalik K, Gumprecht J, Adamczyk P, et al. Association of rs1800471 polymorphism of TGFB1 gene with chronic kidney disease occurrence and progression and hypertension appearance. Arch Med Sci. 2013; 9(2): 230-237, doi: 10.5114/aoms.2013.34418, indexed in Pubmed: 23671432.

9. Buraczynska M, Baranowicz-Gaszczyk I, Borowicz E, et al. TGF-beta1 and TSC-22 gene polymorphisms and susceptibility to microvascular complications in type 2 diabetes. Nephron Physiol. 2007; 106(4): p69-p75, doi: 10.1159/000104874, indexed in Pubmed: 17622752.

10. Śnit M, Nabrdalik K, Długaszek M, et al. Association of rs 3807337 polymorphism of CALD1 gene with diabetic nephropathy occurrence in type 1 diabetes - preliminary results of a family-based study. Endokrynol Pol. 2017; 68(1): 13-17, doi: 10.5603/EP.2017.0003, indexed in Pubmed: 28255976.

11. Korzeniewska-Dyl I, Walczak K, Moczulski D. Genetic variants in SLC9A9 gene coding for soium/hydrogen exchanger 9 are not associated with diabetic kidney disease. Clin Diabetol. 2014; 3(1): 17-21.

12. Shimazaki A, Kawamura Y, Kanazawa A, et al. Genetic variations in the gene encoding ELMO1 are associated with susceptibility to diabetic nephropathy. Diabetes. 2005; 54(4): 1171-1178, doi: 10.2337/diabetes.54.4.1171, indexed in Pubmed: 15793258.

13. Doria A. Genetics of diabetes complications. Curr Diab Rep. 2010; 10(6): 467-475, doi: 10.1007/s11892-010-0147-x, indexed in Pubmed: 20835900

14. Chang YC, Chang EYC, Chuang LM. Recent progress in the genetics of diabetic microvascular complications. World J Diabetes. 2015; 6(5): 715-725, doi: 10.4239/wjd.v6.i5.715, indexed in Pubmed: 26069720.

15. Mooyaart AL, Valk EJJ, van Es LA, et al. Genetic associations in diabetic nephropathy: a meta-analysis. Diabetologia. 2011; 54(3): 544-553, doi: 10.1007/s00125-010-1996-1, indexed in Pubmed: 21127830.

16. Sanui T, Inayoshi A, Noda M, et al. DOCK2 regulates Rac activation and cytoskeletal reorganization through interaction with ELMO1. Blood. 2003; 102(8): 2948-2950, doi: 10.1182/blood-2003-01-0173, indexed in Pubmed: 12829596.

17. Grimsley CM, Kinchen JM, Tosello-Trampont AC, et al. Dock180 and ELMO1 proteins cooperate to promote evolutionarily conserved Rac-dependent cell migration. J Biol Chem. 2004; 279(7): 6087-6097, doi: 10.1074/jbc.M307087200, indexed in Pubmed: 14638695. 
18. deBakker CD, Haney LB, Kinchen JM, et al. Phagocytosis of apoptotic cells is regulated by a UNC-73/TRIO-MIG-2/RhoG signaling module and armadillo repeats of CED-12/ELMO. Curr Biol. 2004; 14(24): 2208-2216, doi: 10.1016/j.cub.2004.12.029, indexed in Pubmed: 15620647.

19. Sharma KR, Heckler K, Stoll SJ, et al. ELMO1 protects renal structure and ultrafiltration in kidney development and under diabetic conditions. Sci Rep. 2016; 6: 37172, doi: 10.1038/srep37172, indexed in Pubmed: 27849017.

20. Leak TS, Perlegas PS, Smith SG, et al. Variants in intron 13 of the ELMO1 gene are associated with diabetic nephropathy in African Americans. Ann Hum Genet. 2009; 73(2): 152-159, doi: 10.1111/j.1469-1 809.2008.00498.x, indexed in Pubmed: 19183347.

21. Craig DW, Millis MP, DiStefano JK. Genome-wide SNP genotyping study using pooled DNA to identify candidate markers mediating susceptibility to end-stage renal disease attributed to Type 1 diabetes. Diabet Med. 2009; 26(11): 1090-1098, doi: 10.1111/j.1464-5491.2009.02846.x, indexed in Pubmed: 19929986.

22. Hanson RL, Millis MP, Young NJ, et al. ELMO1 variants and susceptibility to diabetic nephropathy in American Indians. Mol Genet Metab. 2010; 101(4): 383-390, doi: 10.1016/j.ymgme.2010.08.014, indexed in Pubmed: 20826100.

23. Kim S, Abboud HE, Pahl MV, et al. Examination of association with candidate genes for diabetic nephropathy in a Mexican American population. Clin J Am Soc Nephrol. 2010; 5(6): 1072-1078, doi: 10.2215/CJN.06550909, indexed in Pubmed: 20299368.

24. Turki A, Mzoughi S, Mtitaoui N, et al. Gender differences in the association of ELMO1 genetic variants with type 2 diabetes in Tunisian Arabs. J Endocrinol Invest. 2018; 41(3): 285-291, doi: 10.1007/s40618-017-0734-7, indexed in Pubmed: 28752301.

25. Wu HY, Wu YH, Wang Y, et al. Association of ELMO1 gene polymorphisms with diabetic nephropathy in Chinese population. J Endocrinol Invest. 2013; 36(5): 298-302, doi: 10.3275/8525, indexed in Pubmed: 22842811.

26. Bodhini D, Chidambaram M, Liju S, et al. Association of rs 11643718 SLC12A3 and rs741301 ELMO1 Variants with Diabetic Nephropathy in South Indian Population. Ann Hum Genet. 2016; 80(6): 336-341, doi: 10.1111/ahg.12174, indexed in Pubmed: 27699784.

27. Yadav AK, Kumar V, Dutta P, et al. Variations in CCR5, but not HFE, ELMO1, or SLC12A3, are associated with susceptibility to kidney disease in north Indian individuals with type 2 diabetes. J Diabetes. 2014; 6(6): 547-555, doi: 10.1111/1753-0407.12128, indexed in Pubmed: 24433479

28. Mehrabzadeh M, Pasalar P, Karimi M, et al. Association between ELMO1 gene polymorphisms and diabetic nephropathy in an Iranian population. J Diabetes Metab Disord. 2015; 15: 43, doi: 10.1186/s40200-016-0265-3, indexed in Pubmed: 27761430.

29. Yahya MJ, Ismail PB, Nordin NB, et al. Association of CCL2, CCR5, ELMO1, and IL8 Polymorphism with Diabetic Nephropathy in Malaysian Type 2 Diabetic Patients. Int J Chronic Dis. 2019; 2019: 2053015, doi: 10.1155/2019/2053015, indexed in Pubmed: 30713847.

30. KDOQI. KDOQI Clinical Practice Guidelines and Clinical Practice Recommendations for Diabetes and Chronic Kidney Disease. Am J Kidney Dis. 2007; 49(2 Suppl 2): S12-S154, doi: 10.1053/j.ajkd.2006.12.005, indexed in Pubmed: 17276798

31. Araszkiewicz A, Bandurska-Stankiewicz E, Budzyński A, et al. 2019 Guidelines on the management of diabetic patients. A position of Diabetes Poland. Clin Diabetol. 2019; 8(1): 1-95, doi: 10.5603/dk.2019.0001.

32. Little RR, Rohlfing CL, Sacks DB, et al. National Glycohemoglobin Standardization Program (NGSP) Steering Committee. Status of hemoglobin A1c measurement and goals for improvement: from chaos to order for improving diabetes care. Clin Chem. 2011; 57(2): 205-214, doi: 10.1373/clinchem.2010.148841, indexed in Pubmed: 21148304.

33. Pugliese G, Solini A, Bonora E, et al. The Chronic Kidney Disease Epidemiology Collaboration (CKD-EPI) equation provides a better definition of cardiovascular burden associated with CKD than the Modification of Diet in Renal Disease (MDRD) Study formula in subjects with type 2 diabetes. Atherosclerosis. 2011; 218(1): 194-199, doi: 10.1016/j.atherosclerosis.2011.04.035, indexed in Pubmed: 21612781.

34. Fraser SD, Blakeman T Chronic kidney disease: identification and management in primary care. Pragmat Obs Res. 2016; 7: 21-32, doi: 10.2147/POR.S97310, indexed in Pubmed: 27822135.

35. dbSNP Short Genetic Variations - rs741301. https://www.ncbi.nlm.nih. gov/snp/rs741301\#frequency_tab (Accessed 30 August 2019).

36. Matosin N, Frank E, Engel M, et al. Negativity towards negative results: a discussion of the disconnect between scientific worth and scientific culture. Dis Model Mech. 2014; 7(2): 171-173, doi: 10.1242/dmm.015123, indexed in Pubmed: 24713271. 